\title{
NONTRADITIONAL APPROACH TO STUDYING SCIENCE AND TECHNOLOGY
}

The present paper informs about nontraditional teaching activities which can help teachers and students to reach better results in the studying process. Information and communication technologies (ICT) in physics education can help to increase the effectivity of the teaching process. For students, physical analysis using computer programs is more demonstrative, learning physical equations is quicker, understanding of the physical laws is easier. It is necessary to catch them young. Because of this reason the Children's University of Zilina (CUZ) has been realized in the summer time for children attending elementary school. The questionnaires for children show that it is highly necessary to increase the number of presented experiments, to use multimedia in a larger extent, to develop their imagination and creativity, sense for team work. The interest in nature and technology subjects can be increased by developing the student's imagination and thinking.

"I hear and I forget. I see and I remember. I do and I understand" Confucius quotes

(China's most famous teacher, philosopher, and political theorist, 551-479 BC)

\section{Introduction}

Educating people at the present time is rather conceived as giving students help in building intellectual tools and learning strategies that are necessary in acquiring the knowledge that allows people to think productively about history, science and technology, social phenomena, mathematics, and arts [1]. Since the end of the last century society and education have changed. These changes are caused by the fact that the main goal of learning and teaching in schools was to acquire "learning to learn" skills rather than literacy skills in reading, writing, and calculating. The present situation in the society forces students to have the ability to locate and use information rather than memorize it [2]. The meaning of "knowing" has changed from being able to remember and repeat information to being able to find and use it [3]. Research done in this area has shown that when technology is used in teaching, students are more encouraged to solve problems and new ways in exploring information are discovered [2].

Physics and technology are often considered to be difficult subjects. The main reason is that it is not easy to explain empirical laws and dynamic phenomena in textbooks. Multimedia technologies have shown their potential in the teaching of scientific subjects. New techniques attract student's attention, enabling an easier and rapid process of learning. Students like to use and to work with computers and the modern information and communication technologies (ICT). If we connect the work on computers with studying physics, this form of education will become very attractive for students and we can anticipate that their knowledge in physics will be better [4]. Some university educators try to change the learning process by setting up supplementary courses of physics and using new modern educational methods such as computer presentations, simulations, animations, experiments, and qualitative tasks [5]. Some new courses developed within the ComLab (Computerized Laboratory in Science and Technology Teaching) bring a set of computerized laboratory experiments [6]. A lot of students agree that they enjoyed the studio courses (the Couple Physics Studio, etc.) as compared to the traditional lecture/lab format. Students in these courses are performing as well as or better than students in the traditional courses in spite of the $33.3 \%$ reduction in class contact time [7]. Students will feel more involved and responsible for their own learning experience if we bring more drama into the classroom by re-enacting science, which should help them visualize and remember the lesson [8]. It is very important to use the multimedia tools in other subjects including basic education to make science and technology more appealing and to address the scientific apathy crisis of young people [9]. We can anticipate that the multimedia aid will help to increase the efficiency of the technical education in elementary school [10]. Teachers and scientists from University of Zilina have tried to motivate young people to future study of science or technology through realizing the Children's University of Zilina (CUZ) [11-13].

Advanced methodology and approaches can change the study of nature and technology and it can be a challenge for the teachers and their students.

\footnotetext{
* Peter Hockicko

Department of Physics, Faculty of Electrical Engineering, University of Zilina, Slovakia, E-mail: peter.hockicko@fyzika.uniza.sk
} 


\section{Competencies and their relation to learning outcomes}

The textbook may be a powerful aid to teaching and learning But since learning is related to the goals of education as a whole, textbooks are limited to those which can be expressed in written print. Alternatives to the textbook can be various modules prepared by teachers. Teaching modules can be based on competencies which can focus on the educational capabilities (knowledge, skills, values, etc.) to be developed. The building of a competence means to effectively apply transferred knowledge and skills. The competencies are the capabilities to be developed. They are best regarded as transference abilities involving higher order, analytical, modeling or evaluative skills.

Generally speaking, a school curriculum should achieve three broad educational aims:

- Acquisition of knowledge, skills, abilities or capacities.

- Development of competencies, i.e. the ability to apply the knowledge and skills imparted by education to real-life situations.

- Development of key competencies, i.e. those that are essential in order to participate effectively in the activities within the society [14]

Teaching of the science subjects takes place through the development of lifeskills and the gaining of competencies associated with the interrelationship between knowledge, skills, and values [14].

One of the ways how the development of the key competencies (development of manual skills and intellectual capabilities) can be improved is applying the ICT in the teaching and studying processes.

\section{Taxonomy of Educational Objectives}

In 1956, Benjamin Bloom developed a system of categories of learning behaviour to assist in the design and assessment of educational learning. Skills in the cognitive domain revolve around knowledge, comprehension, and critical thinking of a particular topic. Traditional education tends to emphasize the skills in this domain, particularly the lower-order objectives. Bloom identified six levels within the cognitive domain, from the simple recall or recognition of facts, as the lowest level, through increasingly more complex and abstract mental levels, to the highest order which is classified as evaluation. There are six levels in the taxonomy, moving through the lowest order processes to the highest:

- Knowledge - exhibiting memory of previously-learned materials by recalling facts, terms, basic concepts, and answers,

- Comprehension - demonstrative understanding of facts and ideas by organizing, comparing, translating, interpreting, giving descriptions, and stating main ideas,

- Application - using new knowledge, solve problems arising in new situations by applying acquired knowledge, facts, techniques, and rules in a different way,

- Analysis - examining and breaking information into parts by identifying motives or causes, making inferences, and finding evidence to support generalizations,
- Synthesis - compiling information together in a different way by combining elements in a new pattern or proposing alternative solutions,

- Evaluation - presenting and defending opinions by making judgments about information, validity of ideas or quality of work based on a set of criteria [15].

Bloom's Taxonomy is a reference model for all involved in teaching, learning, training, coaching - in the design, delivery and evaluation of these development methods. The training for technicians may cover knowledge, comprehension, and application, but not concerning oneself with analysis, synthesis, and evaluation, whereas full professional training may be expected to include this and synthesis and evaluation as well.

\section{Interactive tools in teaching and studying process}

Computer modeling that engages students directly in the development of physical models is becoming an increasingly important part of physics education [16]. It was found in previous study [4] that students like to work with computers and that $82 \%$ of them would prefer practical exercises in the subject Physics in multimedia laboratory using computers instead of using classical forms of studying in classroom. Studying using computers (e-learning) compels the students to work in an independent and creative way.

Video analysis of real-world videos gives students a relatively simple way to find basic principles and laws of nature. Students can study real objects which have been captured on digital video. They can record what is important for them, from basketball shots on the playground to jumping, and other favorite activities. It can be used in physics, math, science, and other fields to help to teach concepts, to improve students' understanding of graphs, and to get students involved in their education in a funny way.

Every motion in one or two dimensions can be analyzed using some useful programs such as VideoPoint, Coach, VirtualDub and E-ruler [17], Tracker. One can plot position, velocity, acceleration, and much more as a function of time. As the authors of the VideoPoint say, a careful movie taking and analysis can easily provide results within $5 \%$ of the theoretical values. The ease of using these programs can encourage students to do experiments and to analyze their own videos. These programs develop students' creativity and some students can find new ideas that they can use in analyzing real situations. R. Beichner shows [18] that increased usage of a Video Analysis tool improves students' understanding of kinematics graphs.

The program Tracker - free Java video analysis and modeling tool from Open Source Physics [19] - has been used to analyze a splashed fountain - concretely dropping water to determine position, velocity and finally acceleration (Fig. 1). In a typical video analysis, students capture and open a digital video file, calibrate the scale, and define appropriate coordinate axes. From the number of frames per second the time is deduced, while the position information can be measured in two dimensions from the video image 
after calibration. The motion can be divided into two parts: the horizontal component and the vertical component. These two components can be calculated independently of each other and then the results can be combined to describe the total motion. The only forces acting on the splashed water are the forces of gravity and the air resistance. We can assume that the effect of air resistance is negligible. The vertical position and the velocity are plotted and fitted to see the correlation between the real data and the kinematic equations (Figs. 2-3).

Figure 3 shows that the velocity of the splashed water in the vertical direction changes nearly at the same rate throughout the motion. Because of this the average acceleration in the vertical direction over any time interval equals the instantaneous acceleration at any instant. Therefore, the analyzed motion of a ray of water in the vertical direction can be mathematically described by equations valid for motion at a constant acceleration $a_{y}$

$$
\begin{aligned}
& y=1 / 2 a_{y} t^{2}+v_{0 y} t+y_{0}, \\
& v_{y}=a_{y} t+v_{0 y},
\end{aligned}
$$

where $v_{0 y}$ and $y_{0}$ are the velocity and position at the initial time $t=0 ; y$ and $v_{y}$ position and velocity at some later time $t$.

The position $x$ in the horizontal direction at time $t$ can be described by the equation

$$
x=v_{0 x} t+x_{0},
$$

where $v_{0 x}$ is velocity and $x_{0}$ position in the horizontal direction at the initial time $t=0$. By doing a mathematical fit (Fig. 2) students can find that the trajectory of ray of water is always parabola which can be described with equation

$$
y=a t^{2}+b t+c .
$$

Comparing equations (1) and (4) gives $a=1 / 2 a_{y}, b=v_{0 y}$, and $c=y_{0}$. Then from this fit students have found that $a_{y}=$ $=-9.83 \mathrm{~m} \cdot \mathrm{s}^{-2}$ which is in agreement with value of free-fall acceleration. Analogically the mathematical fit to the velocity of ray of water in vertical direction (Fig. 3) is always a straight line which can be described by equation $y=a t+b$. Comparing this equation with equation (2) students get $a=a_{y}, b=v_{0 y}$. This gives $a_{y}=$ $=-9.7 \mathrm{~m} \cdot \mathrm{s}^{-2}$ which is in agreement with value of free-fall acceleration, too. The second parameter $b=7.24 \mathrm{~m} . \mathrm{s}^{-1}\left(7.14 \mathrm{~m} . \mathrm{s}^{-1}\right)$ corresponds to the initial velocity in the vertical direction.

To do a physical analysis we can think about "Projectile motion" which is a type of two-dimensional motion in the $x y$ plane with constant acceleration whose components are $a_{x}=0$ and $a_{y}=-g$. Usually it is useful to think of this motion as the superposition of two one-dimensional motions: (1) motion in the horizontal direction at constant velocity and (2) free-fall motion in the vertical direction subject to a constant downward acceleration of magnitude $g$.

Using the functions Slope and Area one can demonstrate mathematical connection with the derivative and the integral of func-

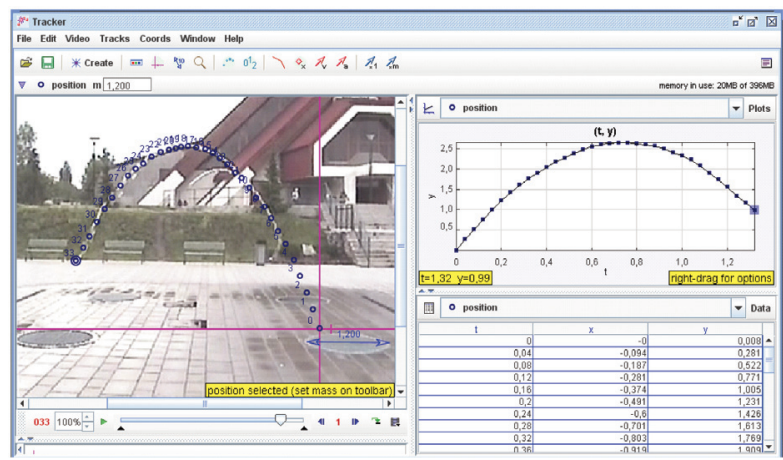

Fig. 1 Analyzing the motion of water moving from a fountain (Zilina, housing estate Vlčince)

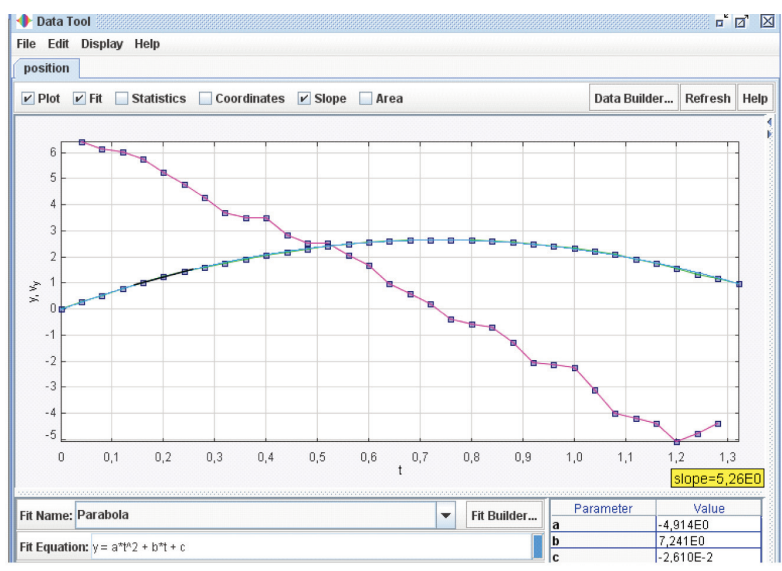

Fig. 2 Time dependences of y-position (blue) and y-velocity (pink). From to the analyzed data $(y(t))$ that were obtained for the vertical direction students could find the parameter a which is connected with the free-fall acceleration $(g=2 * a)$ and parameter $b$ which is connected with initial velocity in vertical direction $\left(v_{y 0}=b\right)$

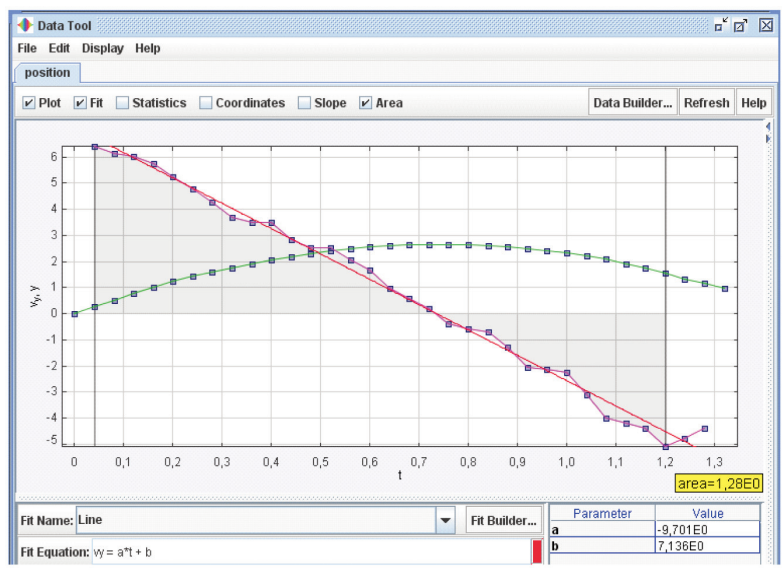

Fig. 3 Time dependences of y-position (green) and y-velocity (pink). From the fit to the equation for $v_{y}(t)$ students found the parameter a which is connected with the free-fall acceleration $(g=a)$ and parameter $b$ which is connected with initial velocity in vertical direction $\left(v_{y 0}=b\right)$ 
tions (derivation of the function $y(t)$ at the $t=0.2 \mathrm{~s}$ shows the value 5.26 which is the same as velocity at this time (Fig. 2); integration of the function $v_{y}(t)$ in the range $t=0.05-1.2 \mathrm{~s}$ shows the value 1.28 which is very close to the y-position at the time 1.2 s (Fig. 3)).

Using this program, the teacher can easily demonstrate the relationships between mathematical functions and the real world. Many of the motions of interest can be described by analytic functions.

These analyses of the real-world videos enable us to realize student's activities on the levels: analysis, synthesis or evaluation of the Bloom's Taxonomy of Educational Objectives.

\section{Motivation of young people}

Any physics teacher would like to teach the students to use physics, logical and technical thinking that they need in practical life. In order for the students to have positive relation to studying physics and technology in future, the basic idea is to inspire and motivate pupils and young people in such a way that they become interested in science. The Children's Universities help us to achieve this goal.

The primary goal of the Children's Universities (CU's) is to undo the reservations the young people have concerning the scientific and academic issues at large. The long-term goal is to awaken interest and enthusiasm of children and young adults, as well. The objectives of the Children's Universities can be summarized as follows:

- Promotion of the interest in science

- Increased face to face contact of children and scientists, to improve the contact with the young people, to open up the university campus to the public

- Increased knowledge about science and scientific careers

- Combating stereotypes and using new technologies

In order to integrate the existing CU's, it was important to establish network of the Children's Universities - EUCU.NET European Children's Universities Network. At present time, 122 CU's from 21 countries, more than 250 registered individuals have initiated such events.

What is the progressive feature that the Children's Universities breed?

- Encouraging children to be curious and to think critically - it is the mainsprings of research and science

- Working with young people in such a way as to help universities to be more responsive

- Making encounters between children and "the university" (as a community of academic staff and students) possible

- Enthralling them with diverse scientific fields (from humanities, to social sciences and natural sciences) and with diverse scientific methods unbiased by commercial interest
- Giving young people an understanding of their future educational choices and options

- Contributing to the enhancement of universities concerning their organizational, didactical, and research development [20]

The Children's University of Zilina (CUZ) has evolved in order to popularize the results of science and technology through lectures and practical exercises given to young people, the schematic discovery of technical subjects, and the stimulation of independent creative thinking. Teachers and scientists want to increase the educational level of the nation with emphasis especially on young generation to show research and development importance for the future public improvement. We want to bring technical science to the attention of the school age children, to eliminate their respect of such subjects as mathematics and physics, and to near them the meaning of research and the application of its results in everyday life. We would like to show young people the way they can learn to think and develop their knowledge, not only to absorb presented knowledge.

The Children's University of Zilina was established in 2005 and it has been taking place at regular intervals: once a year, during one week ( 5 workdays from 8 a.m. till 4 p.m.) in the summer time. Children are divided into teams of up to 20 children per each team. Depending on each single activity, teachers, scientists, and researchers prepare for 8-12 years old children lectures, exercises, demonstrations, and excursions. Our lecturers are the academic staff of university.

There are two "degrees" that can be obtained at the CUZ: the first degree can be granted in the study program "Little Bachelor" to children who completed the 2 nd or 3rd year of the elementary school. They discover basic nature laws. After being granted this degree, children can continue in the following year to obtain the degree "Little Engineer". These groups try to find the way how to apply the laws of nature in technology. Children attend a series of lectures in the morning and object-lessons in the university laboratories in the afternoon. Some of them are: "How do the things move?", "How do the waves move?", "How can I hear?", "How do we see things?", "How to navigate a train", "How does the mobile telephone find Michael?", "How can the temperature be made visible?", "How do the semiconductors light?", "How is film made?", "The fascinating world of chemistry", "About universe and planets", "Science as a game", and so on.

When we asked children in a survey what they liked most about the Children's University, nearly half of them (46\%) chose the laboratory exercises, $22 \%$ would like more lectures, $18 \%$ wanted to work on PC and $14 \%$ wished more outdoor games. $85 \%$ of children prefer the classes in which they can put in practice their own ideas and work actively and creatively, only $15 \%$ would like to work in classes in which they obey commands of the teachers. $57 \%$ of children who graduated in the study program "Little Bachelor" and $53 \%$ of children who graduated in the study program "Little Engineer" said that they wanted to work as a scientist [12] (the total number of the respondents was 600 , years of realization 20052009 ). What is the real situation in our country? Only $6 \%$ of the 
university students studied nature, $29 \%$ technology and $50 \%$ of the university students studied social sciences in the academic year 2005/2006 in Slovakia [21]. The comparison of the teaching activities at the primary school and at the CUZ suggests that if we change the technique (the methods) of teaching, the children who "like it sometimes" (at elementary school) will "always like it" (at the Children's University) [13].

Children's Universities can develop the technical skills and the abilities to learn of the young people and they can improve their knowledge and skills that they will use in their future life.

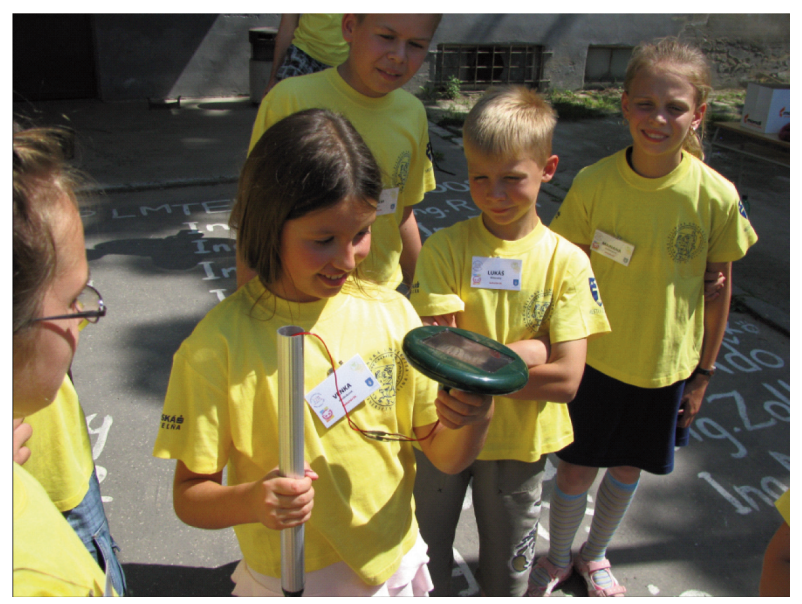

Fig.4 Experimental activity at the Children's University of Zilina

\section{Conclusion}

New multimedia techniques and technologies attract students' attention enabling easier and rapid process of learning. Interactive programs and multimedia tools with simulation and movies develop students' creativity and their creative thinking; encourage them to experiment and to analyze their own movies and videos. Using computer software, teachers can easily demonstrate the relationships between mathematical functions and the real world described by physics. Utilizing useful computer programs in physical analysis of real processes is one of the ways how the key competencies of students can be strengthened. Computing technologies will help in the transformation of a traditional school to a creative one. By changing the activities of the teachers during the lecture, e.g. using interesting experiments and including the activity of the students, one can build in young people interest in studying physics and technology. Full training, teaching, and learning may be expected to include analysis, synthesis or evaluation of Bloom's Taxonomy of Educational Objectives.

It is very important to use these tools also in other subjects including basic education to make science and technology more appealing and to address the scientific apathy of young people. One of the ways where we can start with this is realizing Children's Universities as a form of motivation of young people for the future study of science and technology. Young people expect wide usage of information and communication technologies in education. They eagerly want to work in an active way and to carry out their own ideas. Undoubtedly children of age under 10 have a genuine but hidden interest in natural and technical sciences; they want to become scientist and explorers. However, after several years of education at the elementary level the situation is completely changed. Advanced approaches and methodology aimed at holiday activities at elementary school level have been proved as suitable. It was a challenging opportunity to develop and broaden educational and didactical skills of the university staff cooperated in the Children's University of Zilina.

We try to put a great effort to "make school a game" ("schola ludus") and to involve in the educational process the maximum possible number of senses "... let everything be put forth to all senses. That means things viewable to the sight, hearable to the ear, smelling to the nose, tasteable to the taste, and touchable to the touch; if one can perceive something through several senses at once, let it be put forth to several senses." as a distinguished pedagogue J. A. Komenský said.

\section{Acknowledgements}

This work was supported by the Slovak Research and Development Agency under the contract No. LPP-0195-07 and Slovak Grant Agency KEGA through the project No. 075-008ZU-4/2010.

\section{References}

[1] BRANSFORD, J. D., BROWN, A. L., COCKING, R. R.: How People Learn: Brain, Mind, Experience and School: Expanded Edition, The National Academy Press. Washington, D.C., 2000

[2] SHELLY, G. B., CASHMAN, T. J., GUNTER, R. E., GUNTER, G. A.: Teachers Discovering Computers: Integrating Technology in the Classroom, Thomson Learning, Cambridge, MA, 2001

[3] SIMON, H. A.: Observations on the Sciences of Science Learning, 1996

[4] HOCKICKO, P.: Proc. of the International conference New Trends in Physics - NTF, Brno, 2004, 296

[5] NEMEC, M.: Proc. of the 4th International Symposium Material-Acoustics-Place, Zvolen, 2008, 103

[6] KRISTAK, L., NEMEC, M.: Proc. of the 2009 Information and Communication Technology in Education (ICTE) Annual Conference, Roznov pod Radhostem, 2009, 132

[7] WILSON, J. M.: Studio Teaching: When the Future Becomes the Present, UniServe Science News, 7/1997 
[8] STURM, B.: Science in School, Issue 13, Autumn, 2009, 29

[9] BUSSEI, P., MERLINO, S.: Europhysics News, 34/3, 2003, 116

[10] STEBILA, J.: Journal of Technology and Information Education, Vol. 1, 1/2009, ISSN 1803-537X

[11] HOCKICKO, P.: Modern Trends in Preparation of Teachers of Physics 4, conference proceedings, University of West Bohemia, Plzen, 2009, 111

[12] HOCKICKO, P., TARJANYIOVA, G.: Proc. of the SEFI Conference Physics Teaching in Engineering Education PTEE 2009, Wroclaw University of Technology, 2009, 189

[13] HOCKICKO, P., TARJANYIOVA, G., MUllerovA, J.: Proc. of 16th Conference of Czech and Slovak Physicists, Hradec Kralove 2008, pp. 394, 2009.

[14] HOLBROOK, J., Science Education International, Vol. 20, 1/2/2009, 44

[15] BLOOM, B. S. et al.: Taxonomy of educational objectives: Handbook I, The cognitive domain, 1956

[16] CHRISTIAN, W., ESQUEMBRE, F.: Modeling Physics with Easy Java Simulations, Phys. Teach. 45, 2007, 475

[17] HOCKICKO, P., Proc. of the 2009 Information and Communication Technology in Education (ICTE) Annual Conference, Roznov pod Radhostem, 2009, 103

[18] BEICHNER, R., American Journal of Physics, Vol. 64, 10/1996, 1272

[19] http://www.cabrillo.edu/ dbrown/tracker/

[20] http://eucu.net

[21] RADEK, M. et al.: Higher Education of Slovak Republic (in Slovak). Reality - Problem - Feasible solutions (in Slovak), EPPP - European Public Policy Partnership, 2007. 